\title{
Multi-Body Dynamics Simulation Analysis of Crankshaft Assembly in V- Type 12-Cylinder Large Diesel Based on Adams
}

\author{
Chen $\mathrm{NI}^{1,2, a}$, Lin HUA ${ }^{2,3}$, Zhi-Kui MA ${ }^{1,2}$, and Meng-Lei SUN ${ }^{2,3}$ \\ ${ }^{1}$ Wuhan University of Technology, School of Materials Science and Engineering, Wuhan 430070, \\ China \\ ${ }^{2}$ Wuhan University of Technology, Hubei Key Laboratory of Advanced Technology for Automotive \\ Components, Wuhan 430070, China \\ ${ }^{3}$ Wuhan University of Technology, School of Automotive Engineering, Wuhan 430070, China
}

Keywords: Multi-body dynamics simulation, V-type 12-cylinder engine, Crankshaft assembly, Kinematic characteristic, Load characteristic.

\begin{abstract}
Crankshaft assembly, as one of the most important parts of the engine, always suffers many kinds of cyclic loading during service. Due to the higher requirements for dynamic property of mechanical system, it is necessary to work on multi-body dynamics simulation of crankshaft assembly quick and accurately. The multi-body dynamics simulation analysis was carried out to the crankshaft assembly in V-type 12-cylinder large diesel by dynamics analysis software ADAMS in this work. The kinematic characteristics of piston and load characteristic of connecting rod are obtained via simulations. The comparison of loads on connecting rod between simulation result and analytical calculation result verified the accuracy of multi-body dynamics simulation of crankshaft assembly based on ADAMS. The simulation results can provided basis for finite element analysis of crankshaft and provided guidance for improving the dynamic characteristic of crankshaft assembly.
\end{abstract}

\section{Introduction}

Crank-connecting rod mechanism, as one of the most important parts of the engine, always suffers cyclic loadings during service [1,2]. The operational state of crankshaft assembly can directly affect the performance and service life of engine. The more developments of engineering technology, the higher requirements for dynamic property of mechanical system. Therefore, it is very important to research multi-body dynamics simulation of crankshaft assembly by virtue of advanced method. It is of significance for optimizing the engine components design and improving the dynamic characteristic of crankshaft assembly.

Since the multi-body dynamics has been developed, many researches in multi-body dynamics modeling, design, control, solution strategy and experiment of different mechanical system have been done [3-5]. The multi-body dynamics analysis of crankshaft assembly has been developed from rigid multi-body dynamics to flexible multi-body dynamics in order to improve the accuracy [6]. In former researches, most of multi-body dynamics simulations have been done for crankshaft assembly in single cylinder and in-line type x-cylinder engine $[6,7]$, while the multi-body dynamics simulation for crankshaft assembly in V-type 12-cylinder engine are rare, which is the novelty of this paper.

The multi-body dynamics simulation analysis was carried out to the crankshaft assembly in Vtype 12-cylinder diesel by dynamics analysis software ADAMS in this work. The rigid multi-body dynamics model of crankshaft assembly has been created and simulated to obtain the kinematic characteristics of crank-connecting rod mechanism and load state of connecting rod journal. The accuracy of multi-body dynamics simulation analysis of crankshaft assembly based on ADAMS has been verified by the comparison between simulation results and calculation results by analytical method. It can provided guidance and basis for optimizing the engine components design and improving the dynamic characteristic of crankshaft assembly. 


\section{Multi-Body Dynamics Simulation}

In consideration of the structural complexity of the crankshaft assembly in V-type 12-cylinder internal combustion engine, rigid multi-body dynamic method was used to create the dynamics model of crankshaft assembly in this work. The components materials of crankshaft assembly in this paper are high strength structural alloy steel such as $35 \mathrm{CrMo}$ and $42 \mathrm{CrMo}$ which with high rigidity and little deformation. So accurate analysis results can be obtained by rigid multi-body dynamics simulation.

\section{Virtual Prototype Set Up}

The crankshaft assembly include cylinder piston group (piston and piston pin), connecting rod group (connecting rod and its accessories), and crankshaft group (crankshaft and flywheel, balance weight on it). The crankshaft, with total length of $2263 \mathrm{~mm}$, contains six cranks with the phase angle of 120 between each other. The crankshaft in this four stroke engine rotates $720^{\circ}$ in a working cycle. The CAD software UG was used to create the three-dimensional geometrical model of components and assemble. I.e., the axis of cylinder \#1-\#6 and cylinder \#7-\#12 were arranged by included angle of $120^{\circ}$ and symmetric, the small end of connecting rod was connected with piston group and the big end of connecting-rod was connected with connecting rod of crankshaft, flywheel was connected with end of crankshaft.

The assembled models were imported to ADAMS to analyse. The constraints and kinematic pairs should be set as well as the motion and gas force should be loaded on models before simulating. Figure 1 shows the dynamics models of crankshaft assembly in V-type 12-cylinder large diesel.

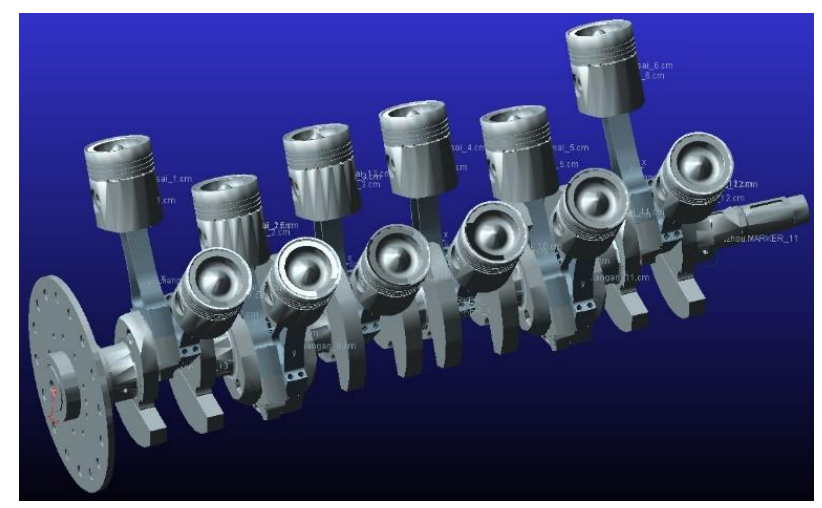

Figure 1. Dynamics models of crankshaft assembly in V-type 12-cylinder large diesel

\section{Simulation Conditions}

Crankshaft was suffered from three kinds of force during its service: cylinder gas force, reciprocating inertia force and rotating inertia force of piston and connecting rod. The gas forces were transmitted to crankshaft by pistons and connecting rods. The inertia forces were contained in model system by setting gravity. Fixed constraint was set between crankshaft and flywheel. Rotation pairs were set between big end of connecting rod and connecting rod, small end of connecting rod and piston pin, piston pin and piston, the seventh main journal and the Ground, respectively. Sliding pair was set between piston and the Ground. Cylindrical pairs were set between all other main journals and the Ground. In ADAMS, the Ground equivalent to the engine body.

The gas force curve of each cylinder is the same, only the phase angle is different. According to distribution of cranks and fire order of engine, cylinder numbering of \#1- \#8- \#5- \#10- \#3- \#7- \#6\#11- \#2- \#9- \#4- \#12 (interval of $60^{\circ}$ ), the gas force of each cylinder could be determined. Figure 2 shows the gas force curves of 12 cylinders in a working cycle. 


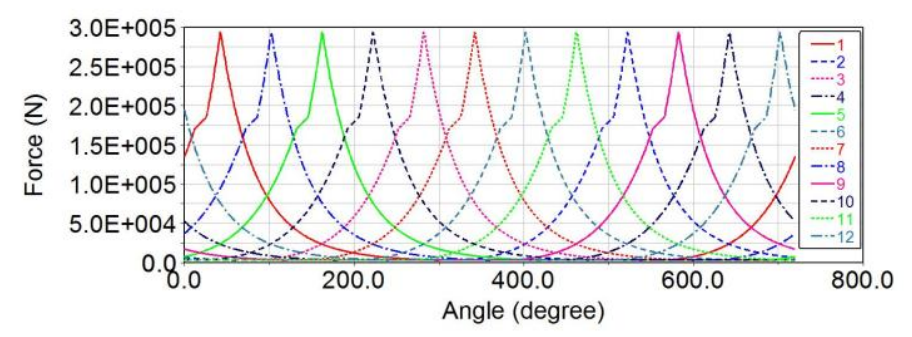

Figure 2. The gas force curves of 12 cylinders in a working cycle

Load spline curves of 12 cylinders were created by importing the gas force data into ADAMS, which could be invoked to loading on the top of piston. Loading on the top of pistons were carried out by Spline Functions, the function of which is AKISPL (First Independent Variable, Second Independent Variable, Spline Name, Derivative Order).

\section{Results and Discussions}

The motion was added on the rotation pair between the seventh main journal of crankshaft and the Ground to make the crankshaft work as its service. According to the engine rated rotation speed of $1500 \mathrm{r} / \mathrm{min}$, the speed of $9000 / \mathrm{s}$ was input to the motion. The time of one work cycle, $0.08 \mathrm{~s}$, was set as simulation time.

\section{Kinematic Characteristics of Piston}

Pistons worked with reciprocating liner movement along the cylinder axis. Figure 3 shows the piston displacement curve along cylinder axis of cylinder \#1. The piston displacement curves of other cylinders are the same, only the phase angle are different. It can be seen from Figure 3 that the piston displacement curve is approximate sinusoid, but valley is more smooth than peak. It indicated that the piston stay near top dead centre (TDC) consuming less time than near upper dead centre (UDC).

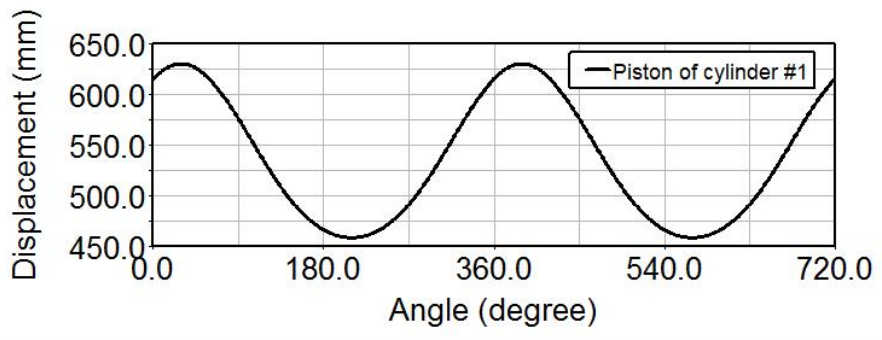

Figure 3. The piston displacement curve along cylinder axis of cylinder \#1

There is an included angle of $60^{\circ}$ between cylinder axis direction and perpendicular direction, so the piston velocity has two coordinate components respectively in perpendicular direction and horizontal direction. Figure 4 shows the piston velocity curve of cylinder \#1 along perpendicular direction and horizontal direction. The piston velocity curves of other cylinders are the same, only the phase angle are different. From Figure 4 it can be seen that the velocity component in horizontal direction is more than which in perpendicular direction. Contrast to Figure 3, the zero velocities appear at TDC and UDC, the maximum velocities appear at the middle of piston travel. It is conformed to the practical situation. 


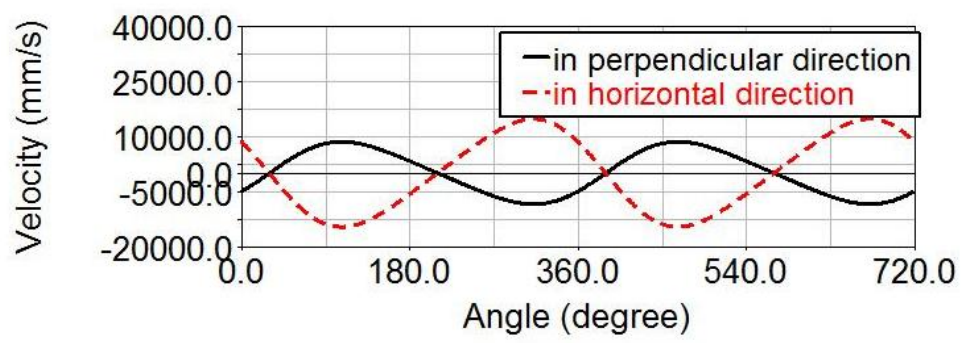

Figure 4. The piston velocity curve of cylinder \#1 along perpendicular direction and horizontal direction

Similar to piston velocity curve, the piston acceleration also has two coordinate components respectively in perpendicular direction and horizontal direction. Figure 5 shows the piston acceleration curve of cylinder \#1 along perpendicular direction and horizontal direction. The piston acceleration curves of other cylinders are the same, only the phase angle are different. It can be seen from Figure 5 that the acceleration component in horizontal direction also is more than which in perpendicular direction. In combination of Figure 3, the acceleration variations of piston at TDC are obvious while which at UDC are gradual. In combination of Figure 4, piston is at zero velocity when it has maximum acceleration and piston is at maximum velocity when it has zero acceleration. It is also conformed to the practical situation.

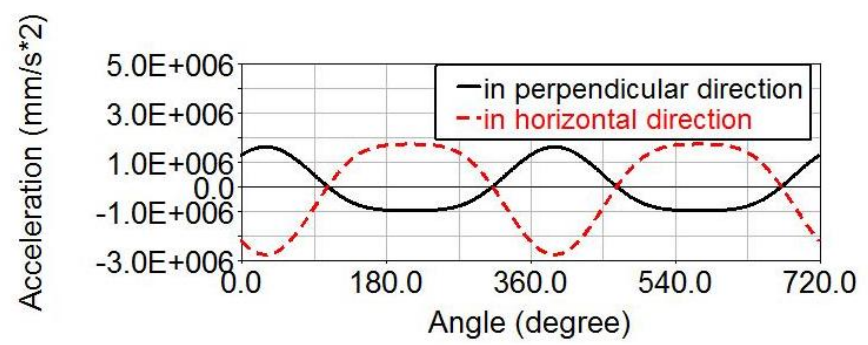

Figure 5. The piston acceleration curve of cylinder \#1 along perpendicular direction and horizontal direction

\section{Load Characteristic of Connecting Rod}

For the crankshaft in V-type diesel, each connecting rod journal is assembled with two connecting rods. Figure 6 shows the load curves of connecting rod journal from connecting rod of cylinder \#1 and cylinder \#7. From Figure 6 it can be seen that the shape of two curves are the same and only the phase angle are different. The load curves from the connecting rod of other cylinder are also the same, only the phase angle are different. The loads from connecting rod of cylinder \#1 and cylinder \#7 are both act on the first connecting rod journal, but this two cylinders working in different stroke. So the acting angles and positions of this two cylinders are different, which change with the rotation of crankshaft. The loads of other connecting rod journal are similar. 

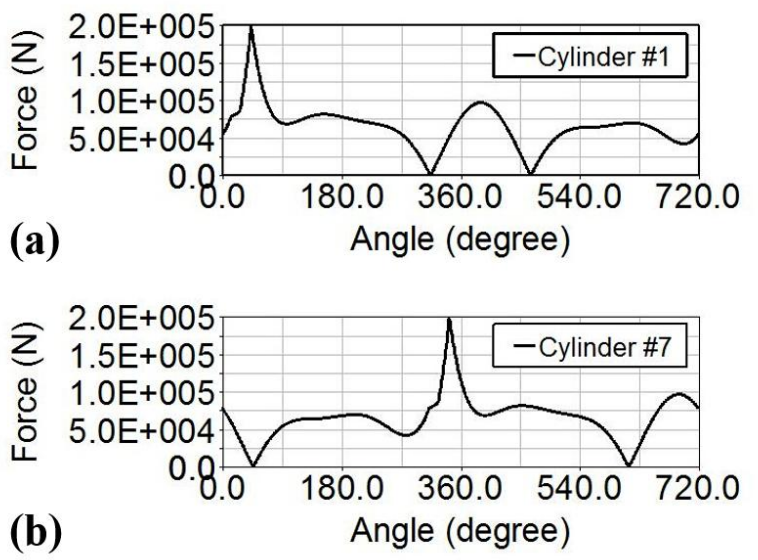

Figure 6. The load curves of connecting rod journal from connecting rod of (a) cylinder \#1 and (b) cylinder \#7

The loads act on connecting rod journals from all connecting rods of cylinders were obtained via multi-body dynamics simulation of crankshaft assembly. The acting positions on connecting rod journals can be determined according to fire order of engine and rotation angles of crankshaft. The loads and acting positions on connecting rod journals can be used for the statics finite element analysis of crankshaft as the load conditions.

\section{Comparison and Verification}

In analytical method for calculating the force, resultant force of many kinds of force should be considered. The rotating inertia force of crank and connecting rod was counteracted by the centrifugal force generated from counterweights. Therefore, in order to simplify the calculate model, the force on connecting rod journal can be considered as the resultant force of gas force and reciprocating inertia force of piston and connecting rod group. Figure 7 shows the schematic diagram of crank-connecting rod mechanism, where $\mathrm{R}$ is crank radius, $\mathrm{L}$ is length of connecting rod, $\lambda=\mathrm{R} / \mathrm{L}$ is crank radius-connecting rod length ratio and $\mathrm{X}$ is displacement of piston.

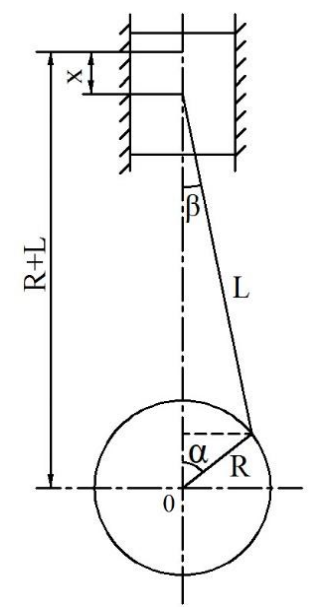

Figure 7. Schematic diagram of crank-connecting rod mechanism

In order to calculate the inertia force, some reasonable assumptions for mass distribution of crank-connecting rod mechanism were made. The equivalent mass of connecting rod with reciprocating motion is expressed as:

$$
m_{j-r o d}=m_{r o d} \frac{L_{1}}{L}
$$


where mrod denotes connecting rod mass, L is connecting rod length, L1 is the distance between mass centre of connecting rod and the centre of connecting rod big end. So the equivalent mass of piston connecting rod sets with reciprocating motion can be expressed as:

$$
m_{j}=m_{p}+m_{j-r o d}
$$

where mp denotes piston assembly mass. The reciprocating inertia force of crank-connecting rod mechanism is expressed as:

$$
F_{j}=m_{j} a=-m_{j} R \omega^{2}(\cos \alpha+\lambda \cos 2 \alpha)
$$

where $\mathrm{a}$ is the piston acceleration calculated by piston displacement and velocity, $\omega$ is angular velocity of crankshaft. The cylinder gas force is expressed as:

$$
F_{g}=\frac{\pi D^{2}}{4}\left(P_{g}-P_{g}^{\prime}\right)
$$

where $\mathrm{D}$ is the cylinder diameter, $\mathrm{Pg}$ denotes the absolute pressure in cylinder and $\mathrm{Pg}$ ' the piston back pressure. The gas force, reciprocating inertia force and their resultant force in a working cycle were calculated by Eqs. (3) and (4). Figure 8 shows the comparison of the load on connecting rod journal obtained by analytical method and multi-body dynamics simulation in a working cycle. The shape of load curve of each cylinder is the same, only the phase angle is different.

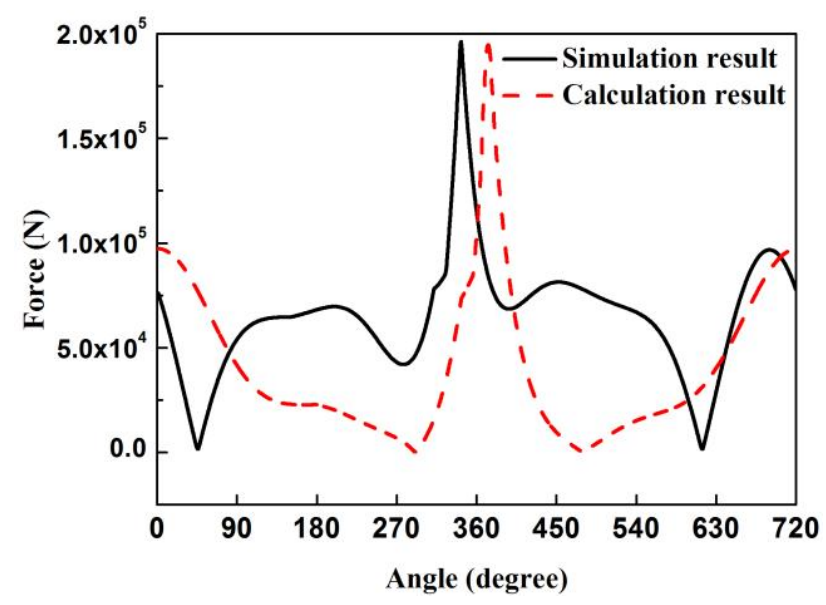

Figure 8 . The comparison of the load on connecting rod journal obtained by analytical method and multi-body dynamics simulation in a working cycle

It can be seen from Figure 8 that the shapes of load curves obtained via two methods are similar and well matched. The error at maximum load is only $1.23 \%$. The angle error of maximum load appears is $31^{\circ}$, i.e. $4.3 \%$. The acceptable error indicated that the multi-body dynamics simulation can reflect the force status of crankshaft conveniently and accurately.

\section{Conclusions}

In this paper, the multi-body dynamics simulation analysis was carried out to the crankshaft assembly in V-type 12-cylinder diesel by dynamics analysis software ADAMS. Then the simulation result was compared to calculation result. The following conclusions can be drawn from this study:

(1) The displacement, velocity and acceleration of piston in a working cycle have been obtained via multi-body dynamics simulation of crankshaft assembly. And it is conformed to the practical situation. Besides, the load of connecting rod journal from connecting rod was obtained which can be used for finite element analysis of crankshaft as load conditions.

(2) The analytical method was applied to calculate the resultant force of gas force and inertia force on connecting rod journal. The simulation result has been compared to calculation result. The 
error at maximum load is only $1.23 \%$, which is acceptable. The accuracy of multi-body dynamics simulation method and reliability of applying to large complex multi-body system have been proved.

\section{References}

1. Do-Hyun Jung, Hong-Jin Kim, Young-Shik Pyoun, Reliability prediction of the fatigue life of a crankshaft, Journal of Mechanical Science and Technology, 23 (2009) 1071-1074

2. J. A. Becerra Villanueva, F. Jiménez Espadafor and F. Cruz Peragón, A methodology for cracks identification in large crankshafts, Mechanical Systems and Signal Processing, 25 (2011) 31683185

3. Wasfy Tamer M, Noor Ahmed K, Computational strategies for flexible multibody systems, Appl Mech Rev, 56 (2003) 553- 613

4. Schiehlen W, Computational dynamics: theory and applications of multibody systems, European Journal of Mechanics A/Solids, 25 (2006) 566- 594

5. Yoo W S, Kim K N, Kim H W, Developments of multibody system dynamics: computer simulations and experiments, Multibody Syst Dyn, 18 (2007) 35- 58

6. LIN Jiansheng, WANG Shan, ZHANG Baohuan, ZHANG Lin, Analysis of Multi-Body Dynamics for an Engine with Multi-Link Mechanism, Journal of Tianjin University, 40 (2007) 640-643

7. Zhang Xiaoming, Wei Dechao, Guo Xiaojie, Dynamics Simulation Analysis of Crank Connecting Rod Mechanism of Multi-cylinder Internal Combustion Engine based on ADAMS, 36 (2012) 95-97 